\title{
Prospective analysis for sustainable tourism in a coastal region of the Gulf of California
}

\author{
O. Arizpe, C. Cabrera \& M. Arizpe \\ University of Baja California Sur, Mexico
}

\begin{abstract}
In 2006, the income for tourism activity in Mexico was nearly 15 billion U.S. dollars, an increase of $5.5 \%$ with respect to 2005. A lack of development planning could produce significant pressure on coastal systems, which could generate a shortage of resources, landscape deterioration, pollution, and loss of biodiversity. Future planning must include the analysis and integration of environmental, social, and economic aspects. This study aims to propose a planning scheme for tourism activities in the coastal zone of Loreto Bay in the Gulf of California, using a prospective analysis. The methods used in this study include micro region zoning through a Geographical Information System (GIS) and capacity of use evaluation. Based on the physical, biological, economical and social characteristics of the study area and the integration of fragility, pressure, and vulnerability indicators, 21 environmental units are proposed. Results showed that the predominant environmental policy would be management within $77.9 \%$ of the total area, while conservation policy would represent $22.1 \%$ of the area. The sites with major anthropogenic perturbation would need an environmental management policy, allowing high capacity tourism with the encouragement of sustainable tourism, but eliminating and further excluding any extreme use or high impact tourism. This methodology allows the determination of areas or zones suitable for tourism activity development. It will be necessary for the Mexican government to define and implement, with integrated criteria, the areas of relevant zones for sustainable tourism development in the Gulf of California with a better characterization, diagnosis, and prospective analysis to meet the long term sustainable development goals in this Gulf of California region.
\end{abstract}

Keywords: sustainable tourism, environmental policies, prospective analysis, Gulf of California, GIS. 


\section{Introduction}

The tourism industry is a growing worldwide economic activity and, in many cases, its importance is crucial to the economy of a particular region. Such is the case in the state of Baja California Sur, Mexico. In 2003, the income through tourism in Mexico was nearly 9.4 billion U.S. dollars, an increase of $5.5 \%$ with respect to 2002 The number of visitors to Mexico in 2003 was 18.8 million (FONATUR [1]).

Tourism is growing in Baja California Sur, especially among foreign visitors. In 2001, for example, there were 3, 215visitors in the state, making it the second most visited Mexican state that year, according to the WTO, (World Tourism Organization). In Loreto, one of the main tourism centers in Baja California Sur (Second only to Los Cabos, the main tourism center, and La Paz, the capital city), there were 54,217 registered visitors that year (B.C.S. State Government [2]).

The economic advantages of tourism have stimulated the creation of federal tourism projects such as the Integral Planned Tourism Center (CIP) LoretoNopoló-Puerto Escondido (Gámez and Montaño [3]) and the Nautical Route of the Sea of Cortes (FONATUR [1]). Strategies are not new to Baja California Sur, but the model on which they are based has generated unequal and unbalanced social, geographic, and sectorial development Moreover, as an additional concern, some of the CIPs were established on or close to current protected areas.

Mexico has decreed natural protected areas as a legal mechanism to promote the conservation and/or preservation of high diversity sites that have unique biological processes. The purpose was to regulate and minimize the potential human impact on these areas, which due to their attractive features were likely to develop tourism activities (Stewart [4]) Without this, the lack of development planning in or adjacent to these spaces could cause significant pressure on the marine and terrestrial systems, which could produce a shortage of resources, landscape deterioration, pollution, and loss of biodiversity, among other effects, with negative repercussions for the future.

A planning process must include the analysis of physical, social, and economic aspects. To achieve that goal, an evaluation is necessary that is based on: 1) the land's capacity to support diverse activities, considering natural and socioeconomic interactions; and 2) potential environmental impacts produced by the development of such activities (SEMARNAP [5]).

The municipality of Loreto was established in 1992 and is located in the central part of the state of Baja California Sur, with an area of 4,878 km2. The study area in question is $515.8 \mathrm{~km} 2$ (Fig.1), determined by the Mexican government, in agreement with the Tourism Secretary and the National Ecology Institute. Since 1982, several studies, carried out from different perspectives, have pointed out that the region is suitable for tourism activities but only under certain conservation policies. 


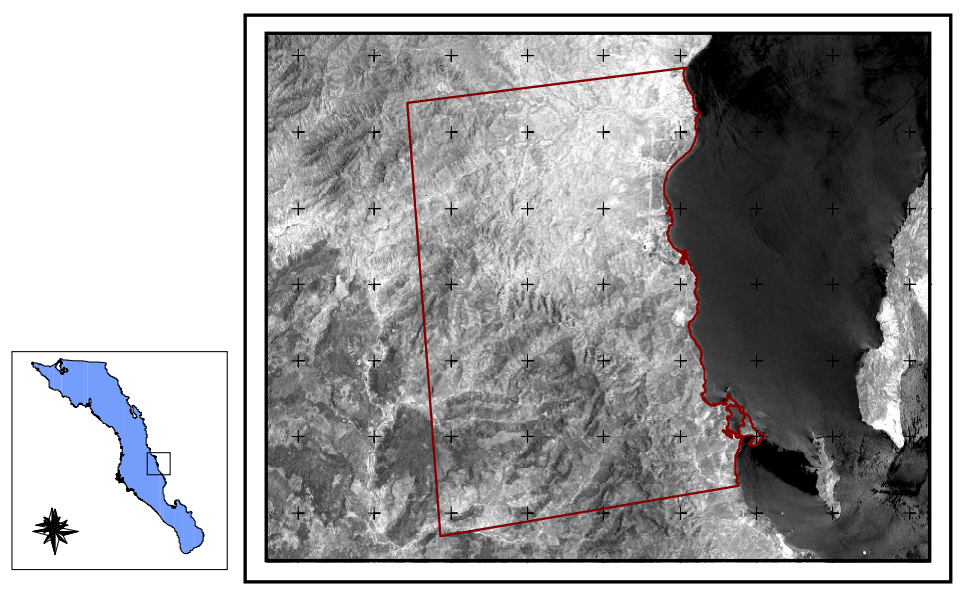

Figure 1: $\quad$ Loreto region showing the study area.

\section{Methods}

Zoning analysis and evaluation of capacity were used. The zoning analysis, through the Ecological Ordering (ecological planning) methodology (SEMARNAT [6]) only addressed its first four phases.

First, the biotic and abiotic systems were described after a search of published material such as journal articles, books, and management programs, as well as statistical information obtained from the National Institute of Geography and Informatics, and the Baja California Sur state government. Information was input into a Geographic Information System (GIS), using ArcView 3.2 software and an ASTER satellite image of 1:50,000 resolution. The diagnosis of the tourism activity utilised current actions, their characteristics and issues, and the places where it was developing. For the prospective phase, the trends of population growth and number of tourists visiting were considered. Finally, in the delimitations of zones phase, environmental areas were defined based on biological, physical, and/or social features using a geographical information system and ArcView 3.2 software. The environmental policy for each unit was determined by the application of pressure, fragility, and vulnerability indicators (SEMARNAT-INE [7]).

The capability evaluation used is known as the weight-rate technique (Gómez-Morín [8]). Attribute valuation for each environmental unit was made by applying the equation:

$$
\mathrm{Ca}=\sum_{\mathrm{i}=1}^{\mathrm{P}} \mathrm{Pia}^{\mathrm{V}} * \mathrm{Via}
$$

where:

$\mathrm{Ca}=$ Capability of the environmental unit to hold activity " $\mathrm{a}$ " 
$\mathrm{n}=$ Number of factors that influence the capability determination

Pia $=$ Weight that reflects the importance of factor " $i$ " over the capability for activity "a"

Via = Value of factor "i" in the unit according to the capability to hold activity "a"

Every factor was weighted according its relative importance (weight) to each other and for each proposed use: where 3 was very important, 2 meant important, and 1 was without any importance. Afterwards, each factor was rated using a nominal scale: $-1,0,1$, representing the condition of the factor for the specific use proposed for that unit, which could be unfavorable, indifferent, or favorable. The result of multiplying both values together, weight and rate, was statistically normalized using a non-parametric method, and separated into four classes of capability limited by a 0.7 standard deviation, giving an equal $25 \%$ of probability to each capability class .

Table 1: $\quad$ Capacity classes for use in an environmental unit.

\begin{tabular}{|c|c|}
\hline Capability Value & Capacity \\
\hline $100.00-75.01$ & Very High \\
$75.00-50.01$ & High \\
$50.00-25.01$ & Medium \\
$25.00-0.00$ & Low \\
\hline
\end{tabular}

Once obtained, the environmental policy and capability values were integrated in a geographical information system, using ArcView 3.2 software. The recommended activities for the units were those with a greater capability value.

\section{Results}

\subsection{Physical, biological, and social characteristics}

The region has weather type $\mathrm{Bw}$, dry with sporadic rain in summer and winter. Average temperature is $22.6{ }^{\circ} \mathrm{C}$, with a maximum of $40{ }^{\circ} \mathrm{C}$ and a minimum of $16{ }^{\circ} \mathrm{C}$. The winds are predominantly from the north and east (López-Espinosa [9]). The Loreto municipality is characterized by the presence of La Giganta Mountain range close to the coastline. This generates short, straight streams with a littoral border of an alluvial plain. Demand for water in Loreto has been increasing and in some cases this demand is greater than the capacity for the aquifers of the region to recharge. The principal uses for water include grazing activities, domestic and urban uses, and hotel and tourism-related requirements such as golf courses.

The study area is composed of $98.7 \%$ natural vegetation, with the presence of sarcocaule shrubs, sarcocrasicaule shrubs, and sarcocaule shrubs with secondary vegetation and mesquite (López-Espinosa [9]). The fauna is abundant and diverse. Important fauna, in terms of conservation and/or ecotourism, includes 
terrestrial mammals, marine turtles, and marine and coastal birds, some of which are considered threatened or in danger of extinction. Ecotourism could facilitate their conservation and bring economic benefits to the local people.

Few settlements are located within the study area and municipality. The total municipal population in 2005 was 11,839 people, and the city of Loreto was the most important settlement, with 10,283 people. The rest of the population is distributed in 22 small towns (INEGI [10]). The economy of urban Loreto is based on the service industry, in contrast with the rural settlements, where the principal economic activity is in the primary sector, including fishing and grazing activities. Tourism is the most important economic activity in the region and in the largest settlements it has displaced fishing as the main activity.

\subsection{Tourist activity diagnosis}

Tourist activities consist of camping, hiking, mule treks and bicycling and are sometimes linked to activities that take place in the marine zone. Most of these activities have been developed by foreigners, mainly from United States and Canada (FONATUR [1]).

Camping is usually associated with kayaking, and has a high season from October to May. Camping also includes trailer camps located in the southern region of the study area during the period December through March, and has numbered from 16 to 50 vehicles. Due to the lack of regulations, the beaches and adjacent areas have deteriorated, showing destruction of plant material, erosion, and pollution. Hiking, mule treks and bicycling are mainly concentrated in the La Giganta Mountain range, with the San Javier mission as one of the favorite destinations. These three activities can usually be undertaken all year round, but because of the weather, especially high summer temperatures, the major tourist season runs from October to May.

The tourism infrastructure consists of hotels, restaurants, car rentals, night clubs, and travel agencies. Transportation services are also offered, as well as ecotourism activities. There are also 24 licensed service providers allowed to work in the protected nature areas. There are 120 service providers registered in the Loreto Bay National Park, and about 29 accommodation venues near the city of Loreto (Loreto Hotel Association [11]).

In the year 2000 , the average hotel occupancy rate was $48 \%$, with a total of 58,474 guests : 15,828 were nationals and 42,650 were foreigners INEGI, [10] Hotel occupancy declined in the following years, with an occupancy rate of $41.8 \%$ in 2001, and 35.9\% in 2002 (FONATUR [1]). In 2003, Loreto had $10 \%$ of all the hotels in the state of Baja California Sur.

\subsection{Zoning}

Four maps were produced for the study area relief, streams, hydrological regions, and anthropogenic modification. Through the integration of these four maps, or GIS layers, 21 environmental units were generated.

According to the criteria explained above, two zoning categories were determined: a) management zones, those with an environmental management 
policy, represented by 7 environmental units; and b) conservation zones, those with an environmental conservation policy, represented by 14 environmental units. (Figs. $2 \& 3$, Table 2).
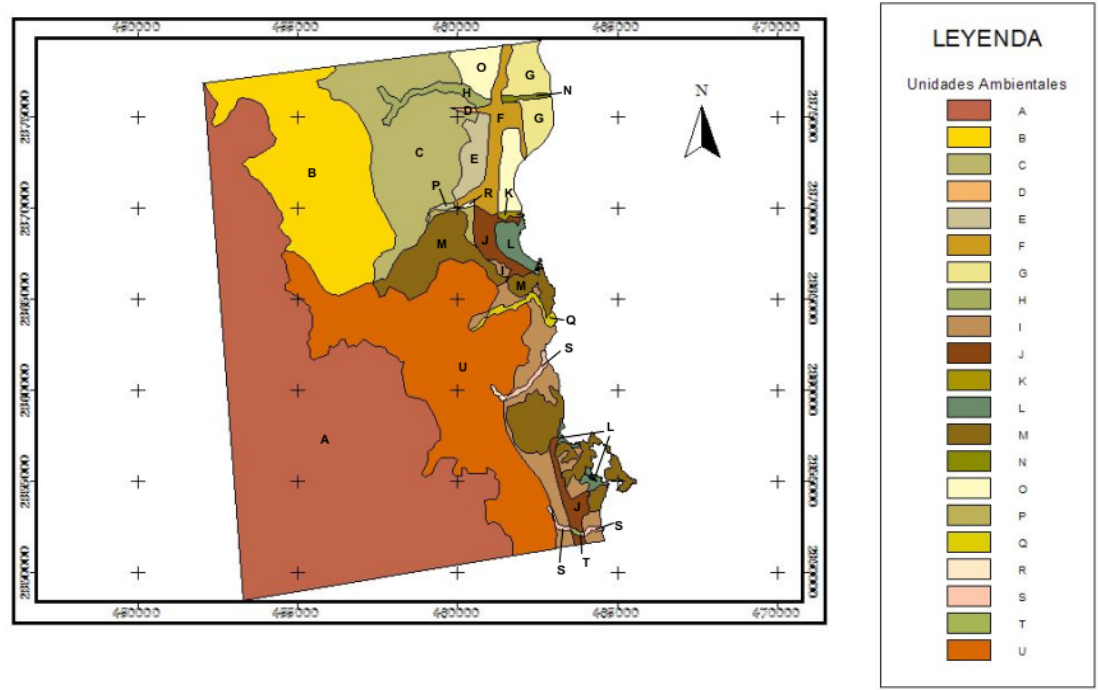

Figure 2: $\quad$ Environmental units.

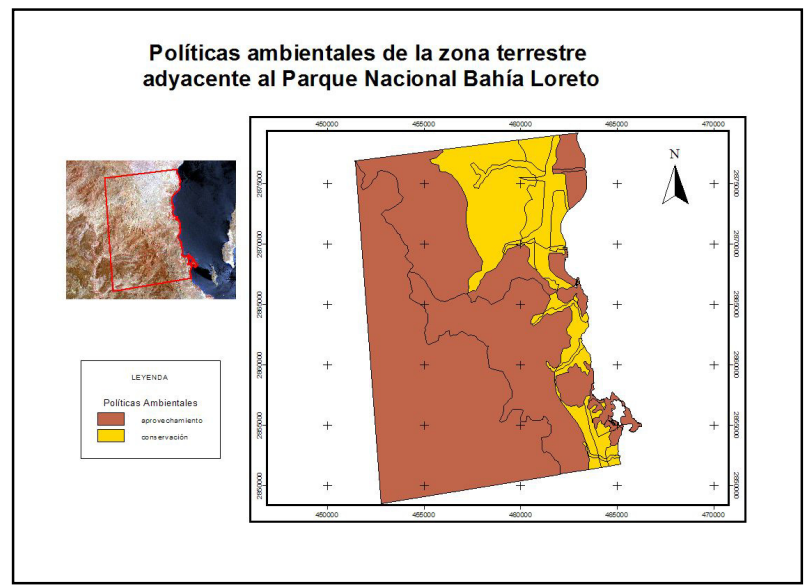

Figure 3: $\quad$ Environmental policies.

Table 2: $\quad$ Environmental policies.

\begin{tabular}{|l|l|l|l|}
\hline Enviromental Policie & No. Of Units & Total Ha. & Percentage \\
\hline Z. Sustainable Use & 7 & 40251.41 & 77.93 \\
Z. Conservation & 14 & 11402.65 & 22.07 \\
\hline
\end{tabular}




\subsection{Evaluation capacity}

With respect to use capacity, all areas that currently have a degree of modification present high capacity for all the tourism activities; for example, Loreto, Nopoló, and Juncalito. The elevated areas have a medium capacity for camping, hiking, and mule treks while the suitability for bicycles is low. Areas with water have capability for tourism activities. The predominant activity that can take place in the zone is camping. For units close to the coast, camping, hiking, mule treks and bicycling are appropriate activities.

The proposed scheme is a result of the integration of the environmental policies and the use capacity of the units . Because of the importance of weather conditions for any activity, the area allows for the undertaking of more than one activity in several of the units . In general, this would mean that there would be no conflict for space or resources. The areas where there are no activities proposed have a low capacity for any activities. In general, low impact activities are proposed. It is desirable to have the kind of tourism where the negative impact on the resources is minimal, with the use of natural resources being compatible with continuous economic growth.

\section{Discussion}

The natural characteristics of the zone make the Loreto region an attractive place for relaxed, "in touch with nature" holidays. There are four main tourist activities that take place on the coast: hiking, camping, mule treks and bicycling with the addition of recreational vehicles along the coast line. Generally, their development depends on weather conditions. Due to the biological richness of the area, there are natural resources with tourism potential, such as bird and whale-watching. These additional activities, if well planned, could be an important source of income for local inhabitants.

In terms of the ecological land use model, the units with a management policy are those with a high anthropogenic modification and with intensive resource use, as in the case with Loreto, Nopoló, and Juncalito. Areas with low modification allow planning and regulation of activities from the beginning and promotion of sustainable development. Conservation areas show medium or partial anthropogenic modification and portions of their resources are still in good condition, suitable for promoting low intensity activities.

According to the this evaluation, in areas with high anthropogenic modification, it is possible to realize any type of low impact activity. Areas with low anthropogenic modification are suitable for one, or a maximum of two, low impact activities. This is because little disturbed areas are more susceptible to negative impacts from the development of an activity.

The study site has, on average, a medium capacity to have many activities. This does not suggest the prohibition of any activity, but it would be necessary to regulate the current and future activities. It is important to emphasize that all the activities should be of low impact; otherwise there is a risk that any efforts will fail and will fragment habitats and destroy the natural attractiveness of the area. 
A significant part of the population of the study area is employed in the tourism sector. This reflects the tourism vocation of the region and is reflected in the depletion of the fishing resources. The tourism activities are mainly concentrated in Loreto, as most of the tourist activities take place or are based there.

Stimulating tourism does not necessarily improve economic conditions for local people. With new large projects such as the Nautical Route of the Sea of Cortes and Villages at Loreto Bay, tourism infrastructure will be built, opening up new jobs. This does not assure a higher income for the inhabitants of the region nor better living conditions. Often, these new positions are occupied by nonlocal people who migrate from the mainland or from the south of the peninsula.

\section{Conclusion and recommendations}

The tourist activities in the area are camping, bicycling, hiking, and mule treks. Problems include the lack of regulation of such activities as well as problems with registration of tourism service providers. Due to the seasonal nature of tourism activities, it is possible to use one site for two or more activities without creating competition for space or resources.

Based on the physical, biological, and social characteristics of the study area, 21 environmental units are proposed. Integration of the information, applying fragility, pressure, and vulnerability indicators, and using satellite images (ASTER), results in policies that would provide management for 7 environmental units and conservation for 14 environmental units. The predominant environmental policy is management with $77.9 \%$ of the total area, while conservation policy represents $22.1 \%$ of the area. Management zones are those with maximum or minimum anthropogenic modification, and conservation zones are those with partial anthropogenic modification.

The capacity of evaluation of the environmental units depends on the anthropogenic modification. Using this methodology allows the determination of areas or zones suitable for tourism activity development. The sites with a major anthropogenic perturbation have a management environmental policy, with a high capacity for tourism activities.

The characteristics of the study area and the results of this paper recommend the encouragement of low impact tourism, evoding and eliminating any extreme use. Highly modified areas, such as Loreto and Puerto Escondido, can support the development of the current four main tourism activities: camping, hiking, bicycling and mule treks. All activities must be regulated. It is necessary to register tourism services providers, all tourism activities, the places where they take place, and the importance of each one. It would also be advisable to investigate potential resources and locations for new tourism activities. Finally, it is imperative that the Mexican government define, with integrated criteria, the area of relevant zones for the development of tourism in the Gulf of California for better characterization, diagnosis, management proposals and o sustainable development of the region. This will make early implementation of management measures possible. 


\section{References}

[1] FONATUR 2004. Proyecto Mar de Cortés. http://www.fonatur.gob.mx

[2] Baja California Sur State Government. Coordinación Estatal de Turismo. 2003.

[3] Gámez, A \& Montaño, B. Diagnóstico Estratégico del Sector Turismo en Baja California Sur. Universidad Autónoma de Baja California Sur (UABCS), México. 277-311 pp. 2003

[4] Stewart, M.C. Sustainable Tourism Development and Marine Conservation Regimes. Elsevier Science Publishers. England. 201-207 pp 1993

[5] SEMARNAP, 1996. Ley General del Equilibrio Ecológico y Protección al Ambiente. México. Ediciones Delma. 444 p. 1996

[6] SEMARNAT Manual del Proceso de Ordenamiento Ecológico. México. 2006

[7] SEMARNAT-INE Ordenamiento Ecológico del Mar de Cortés. http://www.ine.gob.mx

[8] Gómez-Morín, L. Marco Conceptual y Metodológico para la Planificación Ambiental del Desarrollo Costero en México: La Experiencia de Baja California. UABC. Ensenada, B.C., México. 87p. 1994

[9] López-Espinosa de los Monteros, R. 1996. Propuesta de Ordenamiento de las Actividades de la Zona Marina de Loreto, B.C.S., México. 56 p. 1996

[10] INEGI. Conteo 2005. Resultados por localidad B.C.S. http://www.inegi.gob.mx/

[11] Loreto Hotel Association, 2007) Official Web Site of the Loreto Hotel Association. http://www.gotoloreto.com/about.html 